\title{
Antioxidant Capacity of Alcoholic Viscum Album Extract Compared to Vitamin C Antioxidant Capacity
}

\author{
Ahmadi $\mathrm{R}^{1 *}$, Khalili $\mathrm{S}^{2}$, Karimi Ghezeli $\mathrm{Z}^{3}$ \\ ${ }^{1}$ Department of Biology, Faculty of Basic Sciences, Hamedan Branch, \\ Islamic Azad University, Hamedan, Iran. \\ ${ }^{2}$ Department of Biochemistry, Faculty of Basic Sciences, \\ University of Mazandaran,Babolsar,Iran \\ ${ }^{3}$ Department of Pharmaceutical Chemistry, Faculty of Pharmaceutical Chemistry, \\ Pharmaceutical Sciences Branch, Islamic Azad University, Tehran, Iran (IAUPS)
}

\begin{abstract}
Milestone (Viscum album) is a medicinal plant used to treat various diseases. The present study was carried out to determine the antioxidant capacity of different concentrations of ethanol Viscum album leaf extract compared to vitamin C capacity. In this experimental laboratory study, the leaves were collected from RudsarGuilan province. The samples were dried in shadow, and were ground. The obtained powder was extracted using soxhlet method. Ethanol extracts were prepared. Antioxidant capacity was measured using DPPH method. Data were analyzed using ANOVA. The findings demonstrated that ethanol extract of Viscum album has higher antioxidant capacity than vitamin $C$ in lower concentrations; However, antioxidant capacity of the extract decreases when the concentration increases. Conclusively, despite higher concentrations, lower concentration of Viscum album ethanol leaf extract has higher antioxidant capacity compared to vitamin C capacity.
\end{abstract}

Keywords: Viscum album, Ethanol extract, Antioxidant capacity

\section{Introduction}

Viscum album, a semi-parasitic plant, has been used both in traditional and supplementary medicine in the treatment of many diseases. Viscum album extract (European mistletoe), contains immuno-active compounds with dose-dependent cytotoxic activity that has been used as an adjuvant cancer treatment in Europe[1], [2]. The mistletoe extract has also been shown to be an effective complementary drug in the treatment of cancer patients after surgical removal of the primary tumor[3]. The studies suggest that Viscum album extract has sedative, antiepileptic and antipsychotic activity in mice and rats[4]. The research have shown that Viscum album extract seem to be beneficial for the majority of cancer patients [5]. This may result from antioxidant capacity of the plant extract. However, animal experiments have shown that

Viscum album extract may induce cardiotoxicity, urotoxicity and genotoxicity in mice [6]. This study was exerted to determine the antioxidant capacity of different concentrations of Viscum album compared to vitamin $\mathrm{C}$ antioxidant capacity.

\section{Material and Methods}

In this experimental laboratory study, the leaves were collected from Rudsar-Guilan province. The samples were dried in shadow, and were ground. The obtained powder was extracted using soxhlet method. Ethanol extracts were prepared. Antioxidant capacity was measured using DPPH method. Data were analyzed using ANOVA. 


\section{Results}

The findings demonstrated that ethanol extract of Viscum album has higher antioxidant capacity than vitamin $\mathrm{C}$ in lower concentrations; However, antioxidant capacity of the extract decreases when the concentration increases (figure I).

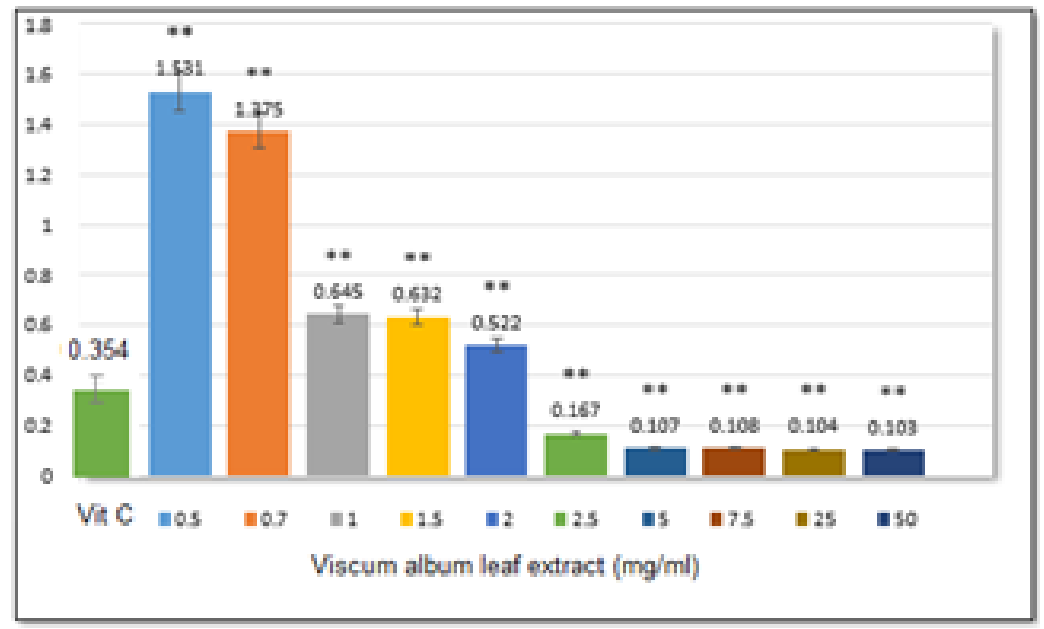

Fig. 1: Antioxidant capacity of different concentrations of Viscum album leaf extract compared to vitamin C (Vit C) antioxidant capacity. ** represents significant difference at $\mathrm{P}<0.05$ compared to Vit $\mathrm{C}$ antioxidant capacity.

\section{Discussion}

Our findings show that ethanol Viscum album leaf extract has significant antioxidant capacity in lower doses. V. album contains phenolic acids, phenylpropanoids and flavonoids with antioxidant and anti-inflammatory activities. Extracts from the plant, especially aqueous, are applied in traditional and official medicine, among others in treating hypertension or arthritis [7]. Previous studies also show that species of Viscum may serve as sources of antioxidants [8]. The studies have shown that Viscum album has potent antihyperglycaemic and antioxidant activity depending on host plant [9].The research have also shown that methanolic extract of Viscum album has antioxidant capacity [10].In addition, Vitamin $\mathrm{C}$ is a highly effective antioxidant [11], [12]. Vitamin $\mathrm{C}$ administration can reduce the oxidative stress [13]-[15]. As we have shown, antioxidant capacity of Viscum album leaf extract is significantly higher than vitamin $\mathrm{C}$ antioxidant capacity, indicating that Viscum album leaf extract can reduce the oxidative stress as well.

\section{Conclusion}

The findings demonstrated that lower concentrations of ethanol Viscum album leaf extract has higher antioxidant capacity than vitamin $\mathrm{C}$ antioxidant capacity; However, higher concentrations of Viscum album leaf extract have lower antioxidant capacity.

\section{Acknowledgment}

This paper has been extracted from the research carried out by the support of grant awarded by Deputy of Research Affairs, Hamedan Branch, Islamic Azad University, Hamedan, Iran. We appreciate all who helped us to exert this study.

\section{References}

[1] Von Schoen-Angerer T, Wilkens J, Kienle GS, Kiene H, Vagedes J. High-Dose Viscum album Extract Treatment in the Prevention of Recurrent Bladder Cancer: A Retrospective Case Series.Perm J. 2015 Fall;19(4):76-83.

[2] Sekeroğlu ZA, Sekeroğlu V.Effects of Viscum album L. extract and quercetin on methotrexate-induced cytogenotoxicity in mouse bone-marrow cells. Mutat Res. 2012;746(1):56-9. 
https://doi.org/10.1016/j.mrgentox.2012.02.012

[3] Maldacker J.Preclinical investigations with mistletoe (Viscum album L.) extract Iscador. Arzneimittelforschung. 2006;56(6A):497-507.

[4] Gupta G, Kazmi I, Afzal M, Rahman M, Saleem S, Ashraf MS, et al. Sedative, antiepileptic and antipsychotic effects of Viscum album L. (Loranthaceae) in mice and rats. J Ethnopharmacol. 2012;141(3):810-6.

https://doi.org/10.1016/j.jep.2012.03.013

[5] Sunjic SB, Gasparovic AC, Vukovic T, Weiss T, Weiss ES, Soldo I, et al.Adjuvant Cancer Biotherapy by Viscum Album Extract Isorel: Overview of Evidence Based Medicine Findings. Coll Antropol. 2015;39(3):701-8.

[6] Sekeroğlu V, Aydin B, Sekeroğlu ZA.Viscum album L. extract and quercetin reduce cyclophosphamide-induced cardiotoxicity, urotoxicity and genotoxicity in mice. Asian Pac J Cancer Prev. 2011;12(11):2925-31.

[7] Nazaruk J, Orlikowski P.Phytochemical profile and therapeutic potential of Viscum album L. Nat Prod Res. 2016;30(4):373-85.

https://doi.org/10.1080/14786419.2015.1022776

[8] Alali FQ, Tawaha K, El-Elimat T, Syouf M, El-Fayad M, Abulaila KT et al.Antioxidant activity and total phenolic content of aqueous and methanolic extracts of Jordanian plants: an ICBG project. Nat Prod Res. 2007;21(12):1121-31. https://doi.org/10.1080/14786410701590285

[9] Orhan DD, Aslan M, Sendogdu N, Ergun F, Yesilada E.Evaluation of the hypoglycemic effect and antioxidant activity of three Viscum album subspecies(European mistletoe) in streptozotocin-diabetic rats. J Ethnopharmacol. 2005;98(1-2):95-102.

https://doi.org/10.1016/j.jep.2004.12.033

[10] AA Oluwaseun, O Ganiyu. Antioxidant properties of methanolic extracts of mistletoes (Viscum album) from cocoa and cashew trees in Nigeria. African Journal of Biotechnology Journal Home.2008:7(17)

[11] Gluhovschi C, Modilcă M, Margineanu M, Gluhovschi G, Velciov S, Petrica L, et al.Surprising good antioxidant status in patients with Balkan Endemic Nephropathy on hemodialysis undergoing vitamin C therapy. A pilot study. Rom J Intern Med. 2014;52(3):158-61.

[12] Hunter DC, Brown R, Green T, Thomson C, Skeaff M, Williams S, et al.Changes in markers of inflammation, antioxidant capacity and oxidative stress in smokers following consumption of milk, and milk supplemented with fruit and vegetable extracts and vitamin C. Int J Food Sci Nutr. 2012;63(1):90-102.

https://doi.org/10.3109/09637486.2011.601286

[13] Li Y, Fang J, Zhou K, Wang C, Mu D, Hua Y. Evaluation of oxidative stress in placenta of fetal cardiac dysfunction rat model and antioxidantdefenses of maternal vitamin $\mathrm{C}$ supplementation with the impacts on P-glycoprotein. J Obstet Gynaecol Res. 2014 ;40(6):1632-42.

https://doi.org/10.1111/jog.12389

[14] Xiong Y, Xiong Y, Zhou S, Sun Y, Zhao Y, Ren X, et al. Vitamin C and E Supplements Enhance the Antioxidant Capacity of Erythrocytes Obtained from Aged Rats. Rejuvenation Res. 2017;20(2):85-92.

https://doi.org/10.1089/rej.2016.1835

[15] Lara-Padilla E, Kormanovski A, Grave PA, Olivares-Corichi IM, Santillan RM, Hicks JJ. Increased antioxidant capacity in healthy volunteers taking a mixture of oral antioxidants versus vitamin C or E supplementation. Adv Ther. 2007;24(1):50-9.

https://doi.org/10.1007/BF02849992 